Journal of Social Sciences 2 (2): 35-40, 2006

ISSN 1549-3652

(C) 2006 Science Publications

\title{
Re-organization Impact on the Telekom Malaysia's International Division Productivity
}

\author{
${ }^{1}$ Ahasanul Haque, ${ }^{2}$ Ali Khatibi and ${ }^{2}$ Khaizura Karim \\ ${ }^{1}$ Department of Business Administration, International Islamic University, Malaysia \\ ${ }^{2}$ Faculty of Management, Multimedia University, Malaysia
}

\begin{abstract}
International Divisions' productivity was perceived to incline towards a downward trend which was contravened in 1996 re-organization objective of Telekom Malaysia. This study aims to analyze the root causes of this setback and recommend the solutions to improve the company's productivity. The method to diagnose the root cause was done through surveys and interviews. The data collection was carried out through questionnaire consisting of 85 questions. Total of 171 respondents from the international employees whom their offices are located throughout Malaysia are responded to the questionnaires. This paper presents a detailed study and analysis on the organization impact on international divisions' productivity of Telekom Malaysia after the re-organization. Theoretical and empirical data are presented about the re-organization and its challenges, independent variables of the strategic organizational change for organization and external environments, the productivity indicators, a model that explains the relationship between organizational factors and productivity, and lastly the re-organization impact on productivity. The respondents that have significant relationship with company's productivity perceived ten independent variables. The three most dominant variables are required immediate strategic actions namely; Quality, External Factors and the Leadership Style to reposition back the company's competitiveness, quality and productivity. The recommended strategic actions to improve the company's productivity these are, all international divisions to acquire professional quality certification near future. To improve and maintain a very good relationship with government authorities need to adoption of transformational leadership style.
\end{abstract}

Key Words: Re-organization, Productivity, International Division, Telekom Malaysia

\section{INTRODUCTION}

Telecommunications competition era in Malaysia first started in 1980s with the introduction of pager companies. This was followed by the emergence of a few cellular operators and trunk radios, which first gave a slightly impact on the Telekom Malaysia's market shares. The competition gradually increases its force as globalization invaded business industries in Malaysia. In 1990s the globalization through the World Trade Organization (WTO) had successfully persuaded the Malaysian Government to liberalize the telecommunications policies. Subsequently the Malaysian Government through the Ministry of Energy, Communications and Multimedia had issued many licenses to new operators. This had allowed the generation and formation of many partnerships and mergers between the local companies and Multinational Corporations (MNCs). This indeed had given the customers the opportunity to freely select which telecommunications operator is able to suit their needs and wants. In order to develop and enhance traits, skills and competencies to meet the customers' demand, Telekom Malaysia had adopted the strategic organizational change that focused on productivity improvements. Telekom Malaysia's management realized the decision to focus on productivity as the means to enhance the competitive advantage to successfully compete against the competitors.

In 1996 Telekom Malaysia including the international divisions had re-organized the whole organization in preparation to face the intense globalization and to survive in the telecommunications industry. However, the effectiveness of the reorganization had never been carried out to gauge the achievement and performance of the international divisions. So the lack of evidence to identify the strength and weaknesses inevitably did not provide opportunity for the international divisions to make adjustments and realign on the right direction. This has significantly affected the productivity as perceived by the management. The management has voiced out their concern of the downward trend in productivity faced by the international divisions for the past few years. Realizing this issue and problem, it then becomes the task of this paper to study the re-organization impact on the company's productivity. In view its above discussion the aim of this study to investigate and determine the paramount internal or organizational factors that have significant impact on the productivity of the international division of Telekom Malaysia.

A majority of companies has undergone the experience of strategic organizational changes in the form of re-organization, mergers and downsizing in the

Corresponding Author: Ahasanul Haque, Department of Business Administration, International Islamic University, Malaysia 
past several years. The main idea of this strategic organizational change is to provide a clear focus and to help in establishing the company's performance improvement in areas of greatest concern and opportunity for change management. This concept is further defined by ${ }^{[1,2]}$ that strategic organizational change is designed to improve organizational efficiency, productivity and effectiveness to remain survive in the business arena.

Appelbaum et al. ${ }^{[3]}$, Mishra et al. ${ }^{[4]}$ and Freeman ${ }^{[5]}$ reckoned that the overall vision, strategy and direction have to come from the top management. Once the vision is established, the senior leaders must develop and create understanding and commitment among organizational members to share the vision of the real identity and the necessary actions to achieve it. Upon implementation of re-organization, the new management through the new leaders has to disseminate the new vision and mission across the board. This will set the direction of the company to achieve in the long term.

Heller et $a .^{[6]}$ indicated senior leaders must articulate a clear vision of the re-organization in order to successfully implement the strategic organizational change. According to Appelbaum et al. ${ }^{[2]}$ mentioned that, they must be responsible for ensuring the change process which is consistent with the mission, vision and values of the organization. It is composed of highly visible, supportive, aggressive and confidence-building leaders who know the business and their people well. The leaders need to understand the strength of its internal capabilities to effectively disseminate the new mission and vision downwards. The successful leadership, as seen by Buchan ${ }^{[7]}$ has to be "strong, committed and guided by clear corporate vision and mission statements.

Appelbaum et al. ${ }^{[8]}$ again depicted that courageous and decisive leadership can inspire an organization to overcome difficult situations or take quick action. The leaders should deal with major resources decisions and new directions, not just day-to-day management, like charting the course and not constantly steering the ship. In contrast, a tendency to overanalyze data or practice 'wait-and-see' attitude may cause a firm to lose ground to competitors and may exacerbate internal problems. Karae et al. ${ }^{[9]}$ argued that new workplace uses fundamental groups to learn, in order for the organization to be able to learn. The groups analyzed the patterns of the needs and wants of the customers in order to be competitive in quality and productivity. There are many professional quality tools available in the market where organization would be able to participate to improve the quality, productivity continuously and finally compete for highest award to develop a higher prestige and reputation for the company. Hoffman et al. ${ }^{[10]}$ said that TQM could be viewed as the organization-wide philosophy requiring all employees at every level of the organization to focus their efforts to help improve each business activity of the organization. TQM acts as the quality tool that focuses on continuous improvement to enhance creativity and innovation, which enables sufficient speed of productivity growth to meet the customers' demands. Therefore, with proper implementation of TQM in the organization, it helps and drives the targets towards achieving the competitive strategies of higher customer services with better quality and productivity. Increase in the level of productivity results in adopting TQM, making TQM the quality tool to continuously improve each business activity within the organization. Thus, there exists a relationship between TQM and the companies' productivity.

Appelbaum et $a l^{[2]}$ argued that, in any reorganization exercise, the companies must plan all aspects of the elimination and reduction of jobs to ensure the expected outcomes. It is essential that employees should be involved in all aspects of reorganization. Cameron ${ }^{[11]}$ suggested that employees should be implicated in the identification of what needs to be changed. They will feel as part of the organization and company requires their existence. Similarly Cameron et al. $^{[12]}$ stated that, the most effective reorganization strategies are those designed and developed by the employees of the firm. Mishra, 1994 proposed that, by actively including majority of the employees during the planning stage, it is possible to avoid the negative consequences felt by the survived employees. It also reduces the number of uncertainty and increases the amount of control over the process ${ }^{[4]}$.

Tvorik et al. ${ }^{[13]}$ in his findings stated that external factors have strong influence on the management decision to adapt for re-organization. The external factors have created many new entrants with highly skilled employees and advanced technology that readily satisfy the customers' needs and wants. As a result, the business industry has become competitive and organizations with strong 'resilience' would survive. Similarly, Appelbaum et al. ${ }^{[8]}$ agreed with this finding and mentioned environmental factors, which can changes in competitors, government regulations, economic conditions and technological advancement are some of the paramount factors that could impede the growth of the company's productivity. Technological innovations by competitors, as well as innovations that unable to implement within the organization itself and its may lead the company to lose its businesses. The rapid change in technology may require the organization to adjust both the structure and the processes. While the ability and flexibility to adapt to any changes of government regulations, customer needs and wants and the economic conditions are considered, the core competency to remain competitive in the business arena need to be considered too. While De Vries and Balazs ${ }^{[14]}$ argued that rather than simply introduce the technology, it is "the administrative impact of the revolutionary transformation in information and communication technology" that has 
impacted the re-organization. The outcome of technological advances has increased the redundancy of middle management, who previously was responsible for collecting, analyzing and transmitting information which are no longer needed. A study done by Powel et $a l .{ }^{[15]}$ the contribution of the external factors in determining the success of the re-organization is so convincing that failure of re-organization has put the blame on it despite the real cause such as the weak businesses and the management decision.

Internal or organization factors may have strong influence, offer significant relationship or difference on productivity. Since productivity is the main concern as the outcome of re-organization, this study is designed to focus on the organization factors. Based on our literature there are four major hypotheses had developed for this study these are:

$\mathrm{H}_{1}$ : There is no significant difference between the identified organizational or known as the internal factors and the company's productivity.

$\mathrm{H}_{2}$ : There is no existence relationship between length of employment and the company's productivity.

$\mathrm{H}_{3}$ : There is no significant gender effect on productivity

$\mathrm{H}_{4}$ : The productivity is the same at all levels of education

\section{MATERIALS AND METHODS}

In the context of this study, the primary data was collected through a set of questionnaire distributed to the company employees who working in the various stages of international divisions. The employees are physically located both centrally (headquarters) and regionally throughout Malaysia covering areas around Klang Valley, East (Sabah and Sarawak) and West (Peninsular) Malaysia. The questionnaire, which was composed of objective questions was designed using five Point Likert-scales and was segmented into nine sections. The questionnaires were distributed about 350 employees both executives and non-executives at international divisions personally, by post express service or e-mail. 171 employees finally responded within the specific timeframe either via post express or by hand. With 171 replies received from the respondents, there were data available for further processing in order to analyze for both descriptive and analytic reports. This paper, five relevant tests were carried out such as Factor Analysis, Pearson Correlation, Independent-sample t-test, ANOVA and the Multiple Linear Regression to analyze the impact of re-organization on the company's productivity. The impact of re-organization experienced by the company is generated and caused by the independent variables that exist prominently in the company that controls and influence the productivity of the company.

\section{RESULTS AND DISCUSSION}

Results from the primary data focused on the descriptive analysis based on the frequency Table 1. Regarding the length of employment as shown in (Table 1), with three categories: firstly, those below 10 years are $32.7 \%$. Secondly, between 10 to 20 years is $42.3 \%$ where as those above 20 years, which is $25 \%$. It showed that, $75 \%$ of the respondents have the opportunity to serve Telekom Malaysia for the next 10 to 20 years.

Table 1: Employee demographic profile

\begin{tabular}{ll}
\hline Descriptions & Percentage (\%) \\
\hline Duration of Employment & 32.7 \\
0-10 Years & 42.3 \\
10-20 years & 25.0 \\
30 and above & \\
& \\
Gender & 80.6 \\
Male & 19.4 \\
Female & \\
& \\
Education Level & 77.4 \\
Non Degree & 22.6 \\
Degree & \\
Types of Employee & \\
Executive & 27.7 \\
Non Executive & 72.3 \\
\hline
\end{tabular}

Respondent's demographic profile is shown in Table 1, out of the total participation of $171,80.6 \%$ were males and $19.4 \%$ were females. As for the education level, $22.6 \%$ were degree holders while 77.4 $\%$ were those with diploma, secondary and primary schools qualifications. Types of employee indicated that, $27.7 \%$ were executives and $72.3 \%$ were nonexecutive. Out of this $27.7 \%$ executives, $5.8 \%$ are managers and above.

Hypotheses testing: Using the multiple linear regression, the significance tests between dependent and independent variables to determine the relationship, whereby independent variables are defined as follows: Leadership style, Quality, Resources, Information technology, Remuneration, Teamwork, Performance, Appraisal, Work stress, External factors, Resistance to IT, HRM, Staff turnover, Quality training, IT training, Routine work.

Results from (Table 2), it showed that, the 'coefficient of determination' or $\mathrm{R}^{2}$ for this 15 variables model is about $91 \%$. The results showed that the existence of a strong linear relationship between the dependent and independent variables. To avoid any coincidence in this finding, ANOVA analysis was done. Prior to analyzing using the ANOVA to determine the significance status of the hypothesis whether there is an over-fitting of independent variables computed by the factor analysis due to many variables are included. In case of over-fitting, this model will perform poorly when applied to a new sample drawn from the same population. 
Table 2: The backward elimination method

\begin{tabular}{lllcc}
\hline Variable & $\mathrm{R}$ & $\mathrm{R}^{2}$ & Adjusted $^{2}$ & Std. Error \\
\hline 15 & .956 & .913 & .902 & .1928 \\
14 & .955 & .913 & .902 & .1929 \\
13 & .955 & .912 & .901 & .1931 \\
12 & .954 & .910 & .900 & .1940 \\
11 & .952 & .905 & .896 & .1979 \\
10 & .948 & .899 & .896 & .2038 \\
\hline
\end{tabular}

The type of analysis used to determine for the overfitting of the independent variables is the backward elimination method. It is an analysis, which eliminates one by one the least useful new variables which is compared to the value of the adjusted value of $\mathrm{R}^{2}$. The conditions used in this case to identify in case of overfitting are: a) Random select $70 \%$ of the cases, means that variables with $t<0.3$ eliminated b) Fit a model and c) $R^{2}$ with more variables is smaller than $R^{2}$ with fewer variables.

By referring to the (Table 2), one of the variables from the total 15 variables is eliminated starting with the lowest $t$ value. Once the least useful variable is taken out, the remaining 14 variables were reanalyzed to create another model summary and the coefficient tables using the multiple regression. From the new model summary and coefficient table, the variable with the lowest $t$ is then identified and taken out. Then these 13 variables were further analyzed. The whole process is repeated with 12,11, 10 variables until all values of $t<0.3$ have been removed as per the condition set above. The value of $\mathrm{R}$ and $\mathrm{R}^{2}$ are then tabulated as shown in (Table 2). This whole process is called the variable selection using 'the backward elimination method'. From (Table 2), as the variables are reduced, the adjusted $\mathrm{R}^{2}$ is eventually decreased in size i.e. adjusted $\mathrm{R}^{2}$ for 15 variables is greater than adjusted $\mathrm{R}^{2}$ for 10 variables. This indicates the model for this paper is not experiencing any such over-fitting. With this analysis, the final number of independent variables that has been confirmed with $70 \%$ random selection without overfitting is ten. With this confirmation, ANOVA analysis was performed.

\begin{tabular}{llllll}
\multicolumn{3}{l}{ Table 3: Coefficient relationship } & & & \\
\cline { 1 - 3 } Description & $\begin{array}{l}\text { Sum of } \\
\text { Squares }\end{array}$ & Df & $\begin{array}{l}\text { Mean } \\
\text { Square }\end{array}$ & F & Sig. \\
\cline { 1 - 5 } Regression & 43.15 & 15 & 2.87 & 77.4 & .0001 \\
Residual & 4.09 & 110 & 0.037 & & \\
Total & 47.24 & 125 & & & \\
\hline
\end{tabular}

From (Table 3), the ANOVA analysis demonstrated that, there is existence of a very strong relationship when it is confirmed that the $F$ statistics value is 77.4 significant at the 0.0001 level. Since $\mathrm{p}<0.05$ and it reflects a significant difference between the ten organization factors and productivity, hence Hypothesis 1 has been rejected. This indicates that there is a significant difference between the identified organizational or internal factors with the company's productivity.

Results from (Table 4), formation of a good model equation is feasible as only three out of fifteen of the $t$ statistics are made up of small values. Additionally, it does not face over-fitting, even at 15 independent variables. This briefly explains that the formation of model equation using 15 new independent variables is possible, however $\mathrm{p}<0.05$ and $\mathrm{t}<0.3$ are the conditions and only the independent variables falling within this range is selected.

The coefficients of ten variables and indicates the ideal selection to form the final model equation. The coefficients under column B in Table 4 are those coefficient relationships between the productivity and the individual variables. The best model equation can be derived from this finding is:

$Y=4.048+0.413 X 1+0.233 X 2+0.212 X 3+0.15 X 4$ $+0.106 \times 5$

$+0.103 X 6+0.09 X 7+0.07 X 8+0.07 X 9-0.07 X 10$

Where: $Y$ is the Productivity, $X 1=$ Quality, $X 2=$ External factors, $\quad X 3=$ Leadership, $\quad X 4=$ Resources, $X 5=$ Remuneration, $\quad X 6=$ Routine $\quad$ Activities, $X 7=$ Teamwork, $X 8=$ Performance Appraisal, $X 9=\mathrm{HRM}$ fair decision, $X 10=$ Work Stress.

For the hypothesis 2, Pearson correlation coefficient is used and results showed that, correlation between the productivity and the length of employment is positive with a very weak correlation coefficient of 0.13 . The coefficient of determination or $\mathrm{R}^{2}$ is then 0.017 and the $p$ value is equal to 0.053 (one tail). This showed that $p>0.05$ its means that there is no evidence of significant relationship between productivity and the length of employment, thus hypothesis $\mathrm{H}_{2}$ has been accepted. The Pearson correlation falls in the weak range category with less than $95 \%$ confidence level (Table 5).

Independent samples t-test carried out to test hypothesis 3 . The results derived from (Table 6), the $p$ value of the equal variances assumed (2-tailed) which is equal to 0.091 , is more than 0.05 thus hypothesis $\mathrm{H}_{3}$ is not rejected signifying that there is no evidence of significant relationship between gender and productivity.

ANOVA analysis is carried out for the hypothesis 4 and 5. The results derived from (Table 7), F statistic is 3.177 with the $p$ value of 0.015 . The ANOVA analysis showed that the value of $p<0.05$, hence the hypothesis $\mathrm{H}_{4}$ is rejected and indicated the existence of a significant difference between productivity and levels of education. This signifies there is evidence of significant relationship between levels of education and the productivity. The level of productivity varies between different levels of education.

Further $\mathrm{F}$ statistic for division and productivity is 6.813 with the $p$ value of 0.005 . Since the value of 
Table 4: Coefficients of 15 variables

\begin{tabular}{|c|c|c|c|c|c|}
\hline \multirow[t]{2}{*}{ Independent Variable } & \multicolumn{2}{|c|}{ Non-standardized Coefficients } & \multicolumn{2}{|c|}{ Standardized Coefficients } & \multirow[b]{2}{*}{ Sig. } \\
\hline & $\mathrm{B}$ & Std. Error & Beta & $\mathrm{t}$ & \\
\hline Constant & 4.048 & .017 & .534 & 235.664 & .000 \\
\hline Leadership & .212 & .017 & .344 & 12.267 & .000 \\
\hline Quality & .413 & 017 & .671 & 23.937 & .000 \\
\hline Resource & .150 & 017 & .245 & 8.726 & .000 \\
\hline Information Technology & 1.847 & 017 & .030 & 1.071 & .286 \\
\hline Remuneration & .106 & .017 & .173 & 6.171 & .000 \\
\hline Teamwork & 9.419 & 017 & .153 & 5.462 & .000 \\
\hline Performance Appraisal & 7.78 & 017 & .127 & 4.515 & .000 \\
\hline Work Stress & -7.250 & 017 & -.118 & -4.204 & .000 \\
\hline External Factor & .233 & 017 & .380 & 13.532 & .000 \\
\hline Resistances faced by IT & 2.428 & 017 & .039 & 1.408 & .162 \\
\hline HRM Decision Making & 7.322 & .017 & .119 & 4.246 & .000 \\
\hline Staff Turnover & 4.977 & 017 & .081 & 2.887 & .005 \\
\hline Quality Training & 4.149 & 017 & .067 & 2.406 & .018 \\
\hline IT training & -1.919 & 017 & -.031 & -1.113 & .268 \\
\hline Routine Activities & .103 & .017 & .168 & 5.986 & .000 \\
\hline
\end{tabular}

Table 5: Correlation between productivity and length of employment

\begin{tabular}{llcc}
\hline Descriptions & & Productivity & Length of Employment With TM \\
\hline Productivity & Pearson Correlation & 1.000 & .130 \\
& Significance, $p$ (1-Tailed) & - & .053 \\
\multirow{3}{*}{ Work Duration in TM } & $\mathrm{N}$ & 171 & 156 \\
& Pearson Correlation & .130 & 1.000 \\
& Significance, $p$ (1-Tailed) & .053 & - \\
& $\mathrm{N}$ & 156 & 156 \\
\hline
\end{tabular}

Table 6: Independent-samples t-test

\begin{tabular}{|c|c|c|c|c|c|c|c|c|c|}
\hline & $\begin{array}{lr}\text { Levene's } \\
\text { Test for } \\
\text { Equality of } \\
\text { Variances } \\
\end{array}$ & & $\begin{array}{l}\text { t-test for } \\
\text { Equality } \\
\text { of means }\end{array}$ & & & & & & \\
\hline & & $\begin{array}{l}\text { Sig. } \\
(1-\text { tail }) \\
p\end{array}$ & $\mathrm{t}$ & $\mathrm{df}$ & $\begin{array}{l}\text { Sig. } \\
\text { (2-tail) }\end{array}$ & $\begin{array}{l}\text { Mean } \\
\text { Difference }\end{array}$ & $\begin{array}{l}\text { Std. Error } \\
\text { Difference }\end{array}$ & $\begin{array}{l}\text { 95\% Confidence } \\
\text { Interval of the } \\
\text { Difference }\end{array}$ & \\
\hline & & & & & & & & Lower & Upper \\
\hline $\begin{array}{l}\text { Equal Variances } \\
\text { assumed }\end{array}$ & 4.856 & .029 & 1.699 & 158 & .091 & .3048 & .1794 & -4.9494 & .6590 \\
\hline $\begin{array}{l}\text { Equal Variances } \\
\text { not assumed }\end{array}$ & & & 1.442 & 38.80 & .157 & .3048 & .2114 & -.1228 & .7324 \\
\hline
\end{tabular}

Table 7: ANOVA analysis on productivity and compare between division and productivity

\begin{tabular}{|c|c|c|c|c|c|}
\hline & Sum of Squares & $\mathrm{df}$ & Mean Square & $\mathrm{F}$ & Sig. P \\
\hline \multicolumn{6}{|l|}{ Productivity: } \\
\hline Between Groups & 8.687 & 4 & 2.172 & 3.177 & .015 \\
\hline Within Groups & 102.531 & 150 & .684 & & \\
\hline Total & 111.218 & 154 & & & \\
\hline \multicolumn{6}{|c|}{ Division and Productivity } \\
\hline Between Groups & 12.927 & 3 & 4.309 & 6.813 & .0005 \\
\hline Within Groups & 97.397 & 154 & .632 & & \\
\hline Total & 110.324 & 157 & & & \\
\hline
\end{tabular}

$\mathrm{p}<0.05$, there is no significant difference between productivity and division hence from this analysis, the hypothesis has been rejected. This signifies there is evidence of significant relationship between divisions and the productivity and the productivity is not the same in all divisions.

\section{CONCLUSION}

This study has identified ten dominant independent variables that have shown significant relationship with the international division's productivity. Subsequently, the best model of the productivity in relation to these ten variables has successfully formulated. Meanwhile all the five hypotheses in this study have also been quantified through the selected tests. From the analysis of productivity indicators for the past three or four years, it has shown a downward trend. The specific independent variables have been diagnosed to cause these downward achievements. As such immediate counterproposal strategic actions have been recommended in order to reposition the international divisions on the right direction.

The paper has determined the ten dominant organizational factors that have significant impact on the productivity of the company. All those independent variables which have been diagnosed by these findings namely, quality, external factors, leadership, resources, 
incentives, routine activities, teamwork, performance appraisal, HRM fair decision and work stress. The findings of this paper indicated that the most prominent independent variables that need immediate action are the quality, external factors and the leadership style. Based on these findings, the proposed strategic action pointed to improve the company's productivity.

Based on the findings, the recommendations have been developed and strategically position the international divisions to continuously improve the core competencies of the internal factors and the competitiveness in order to become viable, dynamic and competitive organization to recapture the losing market shares. So in order to remain in the business, Telekom Malaysia was re-organized the whole organization including the international divisions to improve the company's productivity at present. The impact of quality to serve customer is very damaging. If the current quality of services remains the same, the productivity indicator trends will definitely continue to go down. This will create further dissatisfaction among the customers due to lower quality of services rendered to them.

The external factors if not intelligently, smartly handled, maneuvered and placed under the proper portfolio to successfully negotiate to suit to our needs at sufficient velocity with appropriate authorities. The leaders in the international businesses and those who are involved in the decision making should practice open communication, open-minded, team working, coaching and counseling. Resources can be in the form of materials, staff, incentives, tools, advice, appreciation, relationship and so forth. Lacking of these elements in the organization will reflect the no commitment and interest from the management and leaders. If this is perceived by the employees, as the failure of management, it will put the employees under a lot of constraints and pressures. Finally it would turn off the staff inspiration and drive to work hard for higher productivity. The services provided internationally will involve many other divisions so, team-working is very important in order to make service provision, fault clearance and attendance to complaint on a timely manner. Again, any lacking of teamwork will delay in provisioning high quality service to the customers. This will lead to reduction of the outgoing traffic and affecting the labor and line productivity.

HRM roles are recognized to be important especially in recruiting and terminating the services of employees. What the employees are asking for are fairness in any decision making or selection activities such as promotion exercise, voluntary retirement plan (VRP) selection, training and seminar selection and so forth. If care is not taken, this will develop an indifferent attitude towards HRM activities. However, their main responsibility would not be significantly affected. Productivity will till continue to progress but it may progress at a lower speed. This implies that there are other unidentified reasons why the respondents are currently under stress and constraints. This showed that the respondents have reached the limit from further absorbing any additional workload. This definitely will demoralize and de-motivate the respondents. The indicative signs of declining productivity are very prevalent after the productivity indicators are analyzed. The issues that bugged down the loyal employees have to be addressed accordingly before the damage reaches a situation that is beyond control.

\section{REFERENCES}

1. Appelbaum, S.H., T.G. Close and S. Klasa, 1999. Downsizing: An examination of some successes and more failures. Management Decision, 37: 424436.

2. Mitra, S. and A.K. Chaya, 1996. Analyzing costeffectiveness of organizations; the impact of information technology spending. J. Manag. Inform. Syst., 13: 29-57.

3. Appelbaum, S.H., M. Bethune and R. Tannenbaum, 1999. Downsizing and emergence of self-managed teams. Participation \& Empowerment, 7: 109-130.

4. Mishra, A.K. and K.E. Mishra, 1994. The role of mutual trust in effective downsizing strategies. Human Resource Management, 25: 4-20.

5. Freeman, S.J. and K.S. Cameron, 1993. Organizational downsizing: A convergence and reorientation framework. Organizational Sci., 4: 10-29.

6. Heller, R., 1996. Downsizing's other side. Management Today, pp: 23.

7. Buchanan, P.J., 1997. It's time to take initiative. Trust and Estates, 136: 16-17.

8. Appelbaum, S.H., N. St-Pierre and W. Glavs, 1998. Srtaregic organizational change: The role of leadership, leadership, learning, motivation and productivity. Management Decision, 36: 289-301.

9. Karae, Z.A., 1997. The relative index for the downsizing employees (RIDE) and corporate.

10. Hoffman, J.M. and S. Mehra, 1999. Operationalizing productivity improvement programs through total quality management. Intl. J. Reliability Management, 16: 72-84.

11. Cameron, K.S., 1994. Strategies for successful organizational downsizing. Human Resource Management, 33: 189-211.

12. Cameron, K.S., S.J. Freeman. and A.K. Mishra, 1991. Best practices in white collar downsizing managing contradictions. Academy of Management Executive, 5: 57-73.

13. Tvorik, S.J. and M.H. McGivern, 1997. Determinants of organizational performance. Management Decision, 35: 417-435.

14. De Vries, M. and K. Balazs, 1997. The downside of downsizing. Human Relations, 50: 11-50.

15. Powell, T.C. and A. Dent-Micallef, 1997. Information technology as competitive advantage: the role of human, business and technology resources. Strategic Management J., 18: 375-405. 